and Cuscus, the lumbricals of the manus are all supplied on their superficial surface; a similar arrangement is found in the pes of the fox-bat ; here, however, the deep external plantar also furnishes twigs to the two outer lumbricales. (4) It appears probable from these facts that the lumbricals were all originally supplied on their superficial surface : the deep nerve (ulnar in hand, external plantar in foot) is, on this hypothesis, gradually displacing the superficial (median; internal plantar). This invasion of the deep nerve has advanced further (in the case of the lumbricals) in the human foot than in the hand. The reverse is the case with the innervation of the short muscles of the pollex and hallux. (5) There is a general correspondence between the innervation of a particular lumbrical muscle and that belly of the long perforating flexor of which it is a part this fact is best made out in the case of the first or indicial lumbrical of the hand and the indicial belly of the flexor perforans, which are both supplied by the median; it is also seen in the fourth lumbrical and the belly of the long flexor ending in the tendon to the little finger (both by ulnar); also in the third Iumbrical and annular belly (both of which have typically a double nerve-supply). In the foot and leg this part of the investigation presents special difficulties, which have, however, in a measure been overcome by minute dissections of the posterior tibial nerve and its branches, conducted under water. (Dublin University Reports.)

\section{ON CERTAIN MODERN DEVELOPMENTS OF GRAHAM'S IDEAS CONCERNING THE CONSTITUTION OF MATTER}

I.

THERE is a certain fitness in our selecting this place to do honour to-night to the memory of Thomas Graham. For was in the chemical laboratory of this Institution that Graham carried out, upwards of half a century ago, the experimental investigations which culminated in his memorable discovery of the law connecting the rate of movement of a gas with its density. This law, combined with that of Boyle, which connects the volume of a gas with its pressure, and with the law of Charles, which expresses the relations of the volumes of gases to heat, has done more to give precision to our knowledge of the constitution of matter than all the speculations of twenty centuries of schoolmen.

Graham was made Professor of Chemistry in the Andersonian Institution in 1830, and it was from here that he gave to the world his classical paper "On the Law of the Diffusion of Gases," read before the Royal Society of Edinburgh, December I9, I83. I am fully conscious that my only claim to be regarded as worthy to pronounce this eulogium of Graham arises from the circumstance that I also have had the good fortune to hold the Lectureship of Chemistry in this place; and with forerunners like Birkbeck, Gregory, and Graham, I may well be prond of an honourable and distinguished ancestry. This association with the Andersonian Institution naturally quickened my interest in Graham and his works, and my frequent opportunities of conversation with the late Dr. James Young, of Kelly, who for so many years was its President, and who was, as we all know, also one of Graham's discoveries, and for a long time, both here and in London, one of his most trusted assistants, enabled me to learn much of Graham's personal character and mode of work. On the occasion of the gift of Brodie's fine statue of Graham to the city by Dr. Young it fell to my lot to prepare the short biographical notice of my distinguished predecessor, which, with other papers relating to the matter, is, I understand, deposited in the archives of your Corporation. And I may be pardoned, perhaps, for recalling with what mingled feelings of pride and trepidation I set myself to the execution of that task.

In the preface to the admirable reprint of Graham's papers which we also owe to the filial piety of Dr. Young, the late Dr. Angus Smith has indicated in precise and even luminous language Graham's position in that chain of thinkers which in cludes Leucippus, Lucretius, Newton, and Dalton. Indeed, of all Angus Smith's papers with which I am acquainte there is none, to my thinking, more charming than this little introductory essay of a dozen octavo pages, in which, with unwonted perspicacity, he has defined Graham's place in the history of speculative philosophy. Angus Smith has here crystallised out, as it were, the thoughts of a life-time of literary research and meditation. Pro-

I The Triennial "Graham Lecture," given in the Hall of the Andersonian Institution, Glasgow, on March r6, by Prof. T. E. Thorpe, F.R.S. bably, no man-certainly no contemporary of Graham's-was better fitted by knowledge and by sympathy to form a sound critical estimate of such a position than the biographer of John Dalton. Angus Smith's mind was simply steeped in the old Hellenic philosophy. To him even Kapila was more than a name, and the atomic systems of India matters of more than conjecture or of passing interest. There was much in Smith's intellectual nature to make such inquiries congenial to him. With all his leaning towards objective science he had a Highlander's love of the mystical and a Lowlander's passion for metaphysics. And yet nothing is more admirable than the manner in which, in this essay, these qualities and this wealth of learning are subordinated and held in check, and nothing more striking than the way in which, in a few graphic strokes, done with a master hand, lightly yet firmly, with a consciousness of power and a sense of restraint, Graham's place in the evolution of the atomic philosophy is set forth.

It is here claimed for Graham that he was a true descendant of the early Greeks, and that to him belonged as of right the mantle of Leucippus. Atoms and eternal motion were as much fixed articles of his creed as they were of that of Heraclitus. But with no one of the older Greeks was Graham's thought more in harmony than with that of Leucippus. $\mathrm{He}$, with his wider knowledge of the so-called "elemental" forms of matter, and of the persistency with which the specific properties which we associate with our "elements" are retained, could yet share with the old Greek his conceptions of the ess 2 ntial oneness of matter. It was with Graham, as Smith says of Leucippus, that "the action of the atom as one substance taking various forms by combinations unlimited, was enough to account for all the phenomena of the world. By separation and union, with constant motion, all things could be done,"

In one respect Graham's position as an atomist is unique : no man before him had dedicated his life to the study of atoms and atomic motion. These fundamental ideas are intertwined to make up, so to say, the silver thread which runs through the work of forty years. They were the dominant conceptions of his life. Even in his earliest paper, published when he was just twenty-one, in which he treats of the absorption of gases by liquids, we are able to detect in the phraseology employed that his mind had been already permeated by the notion of atomic movement. That he should be familiar, even at this time, with the conception of atoms in the Daltonian sense is hardly surprising when we remember that he had already come under the influence of Thomas Thomson, whose place in the history of science is probably that of the first great exponent of Dalton's theory of chemical combination. But the idea of motion was never with Dalton an integral part of his theory, nor, in so far as it was necessary as serving to explain the phenomena of chemical union, was it held by Thomson. And this is the more remarkable when we remember that Dalton had discovered for himself the fact of the molecular mobility of a gas, and that his first glimpses of the truth of his great law were obtained by the study of chemical combination among gases. Graham was doubtless cognisant, in a general way, of the speculations of the early Greeks, but there is no evidence in any of his writings, nor has anything been preserved in the reminiscences of his friends and contemporaries, to indicate that he was knowingly influenced by them.

This continuity of idea is indeed the most striking characteristic of Graham's labours; all his work seemed to centralise round this fundamental conception of atomic motion. "In all his work," says Smith, "we find him steadily thinking on the ultimate composition of bodies; he searches after it in following the molecules of gases when diffusing; these he watches as they flow into a vacuum or into other gases, and observes carefully as they pass through tubes, noting the effect of weight and of com. position upon them in transpiration. He follows them as they enter into liquids and pass ont, and as they are absorbed or dissolved by colloid bodies, such as caoutchouc: he attentively inquires if they are absorbed by metals in a similar marner, and finds the remotest analogies, which, by their boldness, compel one to stop reading and to think if they be really possible. $\mathrm{He}$ follows gases at last into metallic combination, and the lightest of them all he makes into a compound with one of the heavier metals, chasing it finally through various lurking-places until he brings it into an alloy and the form of a medal, and puts upon it the stamp of the Mint. Indeed he is scarcely satisfied even with this, and he finds in bodies from stellar places-in meteoric iron -this same metallic hydrogenium which he draws out from its long prison in the form of a gas. . . If we examine his work on Salts and on Solutions we have a similar train of thought. One 
might have slighted the importance which he attached to the water of salts and the temperature at which it was reduced, but in his hands it was a revelation of some of the most mysterious internal phenomena of these bodies.

"A chemist must take great pleasure in following Graham when he seeks the laws of the diffusion of liquids and traces their connections, especially when they lead to such results as he expressed by dialysis, a process founded on a new classification of substances, and promising still the most valuable truths. We see in the inquiry how Graham thought on the internal constitution of bodies, by examining the motion of the parts, and from the most unpromising and hopeless masses under the chemist's hands-amorphous precipitates of alumina or of albumenbrought out analogies which connected them with the most interesting phenomena of organic life. Never has a less brilliant looking series of experiments been made by a chemist, whilst few have been so brilliant in their results or promise more to the inquirer who follows into the wide region opened."

In a short paper entitled "Speculative Ideas respecting the Constitution of Matter," originally published in the Proceedings of the Royal Society for I863, Graham has left us his Confession of Faith upon the subjects to which he had devoted the whole of a thoughtful life. He conceives that the various kinds of matter now recognised as different elementary substances may possess one and the same ultimate or atomic molecule existing in different conditions of movement. Graham traces the harmony of this hypothesis of the essential unity of matter with the equal action of gravity upon all bodies. He recognises that the numerous and varying properties of the solid and liquid, no less than the few grand and simple features of the gas, may all be dependent upon atomic and molecular mobility. Let us imagine, he says, one kind of substance only to exist-p - nderable matter; and further that matter is divisible into ultimate atoms, uniform in size and weight: we shall have one substance and a common atom. With the atom at rest the uniformity of matter would be perfect. But the atom possesses always more or less motion, due, it must be assumed, to a primordial impulse. This motion gives rise to volume. The more rapid the movement the greater the space occupied by the atom, somewhat as the orbit of a planet widens with the degree of projectile velocity. Matter is thus made to differ only in being lighter or denser matter. The specific motion of an atom being inalienable, ligh matter is no longer convertible into heavy matter. In short, matter of different density forms different substances-different inconvertible elements as they have been considered.

It should be said that Graham uses the terms "atom" and "molecule" in a wider sense than that which the limitations of modern chemistry have imposed upon them, and that he is referring to a lower order of molecules or atoms than those which more immediately relate to gaseous volume. The combining atoms of which he conceives the existence are not the molecules of which the movement is sensibly affected by heat with gaseous expansion as the result. According to Graham, the gaseous molecule must itself be viewed as composed of a group or system of the inferior atoms, following as a unit laws similar to those which regulate its constituent atoms. $\mathrm{He}$ is in fact apply ing to the lower order of atoms ideas suggested by the gaseous molecule, just as views derived from the solar system are extended to the subordinate system of a planet and its satellites.

We cannot as yet fix any limit to this process of molecular division. To Graham the gaseous molecule is a reproduction of the inferior atom on a higher scale. The diffusive molecules, the molecules or systems which are affected by heat, are to be supposed uniform in weight but to vary in velocity of movement in correspondence with their constituent atoms. Hence the molecular volumes of different elementary substances have the same relati on to each other as the subordinate atomic volumes of the same substances.

On this basis Graham builds up a conception of chemical com bination. He points out, in the first place, that these more and less mobile or light and heavy forms of matter have a singular relation connected with equality of volume. Equal volumes of two of them can coalesce together, unite their movement and form a new atomic group, retaining the whole, the half, or some simple proportion of the original movement and consequent volume.

Chemical combination thus becomes directly an affair of volume and is only indirectly connected with weight. Combining weights are different because the densities, atomic and molecular, are different. The volume of combination is uniform, but the fluids measured vary in density. This fixed combining measure-Graham's metron of simple substances-weighs I for hydrogen, I 6 for oxygen, and so on with the other "elements."

Graham, however, points out that the hypothesis admits of another expression. Just as in the theory of light we have had the alternative hypotheses of emission and undulation, so in molecular mobility the motion may be assumed to reside either in separate atoms and molecules, or in a fluid medium caused to undulate. A special rate of vibration or pulsation originally imparted to a portion of the fluid medium enlivens that portion of matter with an individual existence, and constitutes it a distinct element or substance.

The idea of the essential unity of matter finds its analogy, to Graham's thinking, in the contintity of the so-called physical states of matter. He clearly perceived that there is no real incompatibility in the different states of gas, liquid, and solid. These physical conditions are, indeed, often found together in the same substance. The liquid and the solid conditions supervene, as Graham puts it, upon the gaseous condition rather than supersede it. They do not appear as the extinction or suppression of the gaseous condition, but as something superadded to that condition. Graham conceives that the three conditions (or constitutions) probably always co-exist in every liquid or solid substance, but one predominates over the others, just as the colloidal condition or constitution which intervenes between the liquid and crystalline states extends into both, and probably affects all kinds of solid and liquid matter in a greater or less degree. Hence, to Graham's thinking, the predominance of a certain physical state in a substance appears to be a distinction analogous to those distinctions in natural history which are produced by unequal development. Liquefaction or solidification does not involve the suppression of the atomic or molecular movement but only the restriction of its range.

Such then are Graham's ideas, formulated in 1863 , respecting the probable constitution of matter. I have purposely stated them in great detail, and for the most part in Graham's own words. The paper is very short, but it has evidently been put together with great care. It is impossible not to be struck with the evidence it affords of Graham's insight, his grasp of principles and power of co-ordination. Consider, for example, what he says respecting the continuity of the so-called physical states of matter, and bear in mind upon what an extremely small experimental basis it rested at that time. The observations of Caignard Latour were almo: $t$ forgotten, or at all events their significance was not understood. The classical work of Andrews was not yet published. And yet this work and that of a dozen experimentalists in France, Russia, and Germany, has only served to confirm and expand Graham's fundamental conception. The whole paper shows Graham in a very different light from that in which the student of to-day might be apt to regard him. The greater number of his memoirs are mainly the records of measurements, but Graham was not a great measurer in the sense in which we apply that term to such men as Regnault, Magnus, or Bunsen. Very little of his work was done by his own hands, and it must be confessed that the earlier experimental portion was occasionally intrusted to apparently inexperienced assistants. Graham had, however, the förscherblick which characterises the true investigator, and he possessed a really marvellous faculty of sifting out the small grain of fact which often lay hidden beneath a mass of imperfect observation. And yet he was in no hurry to theorise. He patiently added fact to fact, repeating and verifying his observations long after he had got an inkling of the truth towards which they were tending. He laboured like Faraday, ohne Hast, ohne Rast, and his work is a monument of patient, concentrated thought, and of a singleness of purpose which never swerved.

"Experimentarian philosophers" of Graham's type (to use a phrase which Hobbes of Malmesbury once flung at the progenitors of the Royal Society) have very similar intellectual tendencies. One is insensibly led to compare Graham with the greatest of our English atomists-John Dalton. If you will turn to Dr. Henry's "Life of Dalton," and read the charming analysis of Dalton's mental characteristics, made by one who knew him well and who had studied him carefully, you will find that practically all that is there stated is equally applicable to Graham. Both men were pre-eminently endowed with the faculty of contemplating abstract relations of space and number, and each began his researches with the expectation that all empirical phenomena were to be brought under the control of mathematical laws. Thus Dalton strove to prove that the 
changes produced in the gaseous and liquid states of matter vary as the square, cube, or some other simple function of the temperature; Graham, in like manner, sought to show that the movement of his diffusive molecules, whether in liquids or in gases, was related to some equally simple function of their mass. Henry says of Dalton that "his inmost mental nature, and all its outward manifestations were in the language of the German metaphysicians, emphatically subjective. Thus in special or objective chemistry he has left absolutely no sign of his presence; no great monograph on an individual body and its compounds; no memorable analysis of a substance deemed simple into yet simpler elements ; no new element-no Neptune-added to the domain of chemistry." Every word of these sentences could be applied with equal truth to Graham. The tendencies of both men were essentially introspective. Each was capable of the most patient concentrated thought and of steady prolonged attention, wholly abstracted from external objects and events. I have heard the late Dr. Young narrate the most extraordinary instances of Graham's power of mental abstraction. Dalton said of himself that, "If I have succeeded better than many who surround me, it has been chiefly, nay, I may say, almost solely, from unwearied assiduity. It is not so much from any superior genius that one man possesses over another, but more from attention to study and perseverance in the objects before them, that some men rise to greater eminence than others."

It seems like a contradiction in terms when we reflect for a moment upon the characteristic features and tendency of his work, to say that Graham, like Dalton, was utterly devoid of the quality we call imagination. Henry says of Dalton that imagination had absolutely no part in his discoveries; except, perhaps, as enabling him to gaze, in mental vision, upon the ultimate atoms of matter, and as shaping forth those pictorial representations of unseen things by which his earliest as well as his latest philosophical speculations were illustrated. Graham would not allow his fancy even that amount of play. Even in the speculative essay from which I have quoted so largely, it seem; as if every word had been weighed and every sentence put together with slow laborious thought. This passionless aspect of his work seems to have greatly impressed Angus Smith, himself a man of lively sympathy and of quick susceptibility. "His works," says Smith, "are full of care, but not of joy."

$$
\text { ( } T o \text { be continued.) }
$$

\section{SCIENTIFIC SERIALS}

American Fournal of Science, March.-On the absolute wavelength of light, by Louis Bell. The experiments here described were undertaken with a view to check the results obtained by $\mathrm{C}$. S. Pierce for Prof. Rowland's great map of the solar spectrum, and to furnish a value of the absolute wave-length as nearly as possible commensurate in accuracy with the micrometrical observations. For the wave-length of D, at $20^{\circ} \mathrm{C}$. and $720 \mathrm{~mm}$. pressure, Mr. Bell obtains 5896.08 , or in vacuo 5897.71 , as compared with $5896 \cdot 22$, Rowland's micrometer measure from Pierce's preliminary result, and 5895.89, Thalèn's correction of Ångström, both in air at ordinary temperature and $760 \mathrm{~mm}$. pressure. But neither of these was corrected for errors in the gratings; hence, obviously, the cause of the discrepancy.-On the relative wavelength of the lines of the solar spectrum, by Prof. Henry A. Rowland. This measurement of the relative wave-lengths of the spectrum and its reduction to absolute wave-lengths by some modern determination has been undertaken in connexion with the photographic map of the solar spectrum on which the author has been engaged for several years, and which is now finished from the extreme ultra-violet wave-length 3200 down to wavelength 5790. Appended are tables of coincidences and of wave-lengths of standard lines. - The norites of the "Cortlandt series" on the Hudson River, near Peakskill, New York (continued), by G. H. Williams. Here are studied the mica norites, the angite norite (hyperite), pyroxenite, and the iron ore and emery in the Cortlandt norite. Owing to incipient alteration, easily visible under the microscope, the West-Chester County emery appears to be of less commercial value than that of Asia Minor.-Natural solutions of cinnabar, gold, and associated sulphides, by George F. Becker. In the course of investigations on the geology of the quicksilver deposits of the Pacific slope, the author has made some studies, here detailed, on the question of the state of combination in which quicksilver is dissolved in natural waters. The solubility of zincblende, pyrite (marcasite), copper sulphides, gold, and other associates of cinnabar, is incidentally examined, the quantitative analysis involved in the process being made by Dr. W. H. Melville.-Fluviatile swamps of New England, by N. S. Shaler. In examining the freshwater swamps of this region, the author has carefully studied the geographical distribution of those formed along the banks of rivers. Although the inquiry is mainly limited to the post-glacial changes in the valleys trending northwards, much light is incidentally thrown on the pre-glacial altitude of the continent. It is made evident that these valleys could not have been excavated by streams of their present slope; hence the inference that the descent of the northward flowing rivers must have been more rapid in pre-glacial times than at present ; in other words, this part of the continent was at that time relatively less elevated in its northern parts than it is at present.-On the Mazapil meteoric-iron which fell on November 27, I 885, by William Earl Hidden.--On observations of the eclipse of August 18, 1887, in connexion with the electric telegraph, by Prof. David P. Todd. Referring to his remarks in the Proceedings of the American Academy of Arts and Sciences for 1881, p. 359, the author points out how the proposed method of telegraphic transmission of important observations might be adopted during the eclipse of August 18 next.-On two new meteorites from Carroll County, Kentucky, and Catorze, Mexico, by George F. Kunz. The Kentucky iron has some ethnological interest in connexion with the ornaments of meteoric iron occurring in the mounds of the Little Miami Valley, Ohio, all apparently belonging to one and the same meteoric fall. The Catorze mass, weighing 92 pounds, was found near Catorze, San Luis, Potosi, in 1885. It is one of the caillite group of Stanislas Meunier, and shows the Widmanstätten lines very finely. Analysis: $\mathrm{Fe} 90^{\circ} 09$; $\mathrm{Ni}$ and $\mathrm{Co} 9{ }^{\circ} 07 ; \mathrm{P} 0.24$; with specific gravity $7^{\circ} 509$.

Rivista Scientifico-Industriale, February.-On the cause of the electric discharge accompanying thunderstorms, by Prof. G. Guglielmo. The views of Ermann and Peltier are here subjected to close scrutiny, and shown to be inadequate to account for these electric phenomena.-On the variations in the electric resistance of antimony and cobalt in the magnetic field, by Dr. G. Faé. The author's researches show that, apart from the intensity of the observed effects, antimony behaves in the way determined by Righi for bismuth, and cobalt in the way determined by Thomson for iron and nickel.

Rendiconti del Reale Istituto Lombardo, February.-Summary of the meteorological observations recorded in the Brera Observatory, Milan, during the year I886, by $\mathrm{E}$. Pini. The daily, monthly, and annual means are tabulated for the atmospheric pressure, temperature, rainfall, velocity, and direction of the winds throughout the year. - Meteorological observations for the month of January, 1887 , at the same Observatory.

\section{SOCIETIES AND ACADEMIES LONDON}

Royal Society, March Io.-." Note on Induction Coils or "Transformers.'" 'By John Hopkinson, M.A., D.Sc., F.R.S.

"Note on the Theory of the Alternate Current Dynamo." By John Hopkinson, M.A., D.Sc., F.R.S.

March I7. - "The Embryology of Monotremata and Marsupialia." Part I. By W. H. Caldwell, M.A., Fellow of Gonville and Caius College, Cambridge. Communicated by Prof. M. Foster, Sec. R.S. (Abstract. ${ }^{1}$ )

(I) The Egg-membranes. - In Monotremata, in very young ova, a fine membrane exists between the single row of follicular cells and the substance of the ovum. This membrane, which I will call the vitelline membrane, at first increases in thickness with the growth of the ovum, and through it pass numerous fine protoplasmic processes connecting the protoplasm of the follicular cells with that of the ovum, and serving to conduct food granules, which, appearing in the neighbourhood of the nuclei of the cells, travel thence to the ovum; food granules also appear in the neighbourhood of the germinal vesicle, and travel away from it: hence the horseshoe-shape of the yolk-mass as seen in section.

I The author being at the present time in Australia and so unable to correct the proof of this abstract, I have undertaken this duty. In doing so $I$ have ventured, for the sake of what appeared to be increased clearness, to introduce into $\$$ I some modifications of the author's manuscript, being guided therein by the author's more detailed account given in the fuller
paper,-M. FOSTER, Sec. R.S. 